\title{
Investigating English Speaking Problems of Lawyers in Court Proceedings
}

\author{
Iqra Majeed Baloch \\ MS Scholar, Mehran University of Engineering \& Technology, Jamshoro \\ Shabana Gul Tunio \\ Assistant Professor, Sindh Agriculture University, Tandojam \\ Sadia Memon \\ Lecturer, Mehran University of Engineering \& Technology, Jamshoro \\ Nishfa Rajper and Iram Panhwar \\ MS Scholars, Mehran University of Engineering \& Technology, Jamshoro
}

\begin{abstract}
Lawyers of Pakistan are facing numerous challenges while performing at their workplaces. One of the major challenges is proficiency in English language which plays the key role in getting justice. The aim of this paper is to investigate the English-speaking problems faced by the lawyers in court proceedings of Hyderabad, Sindh. For this purpose, qualitative methodology has been used in which Semi-structured interviews were conducted from $(n=5)$ lawyers. Convenient sampling was used to select the participants based on their convenience. Thematic analysis was done for analyzation of the data. Findings of the data revealed that lawyers were facing numerous English-speaking problems such as grammatical mistakes, vocabulary error, inappropriate use of sentences and so on.
\end{abstract}

Keywords: English-speaking, Lawyers, Court Proceedings, Problems.

DOI: $10.7176 /$ JLLL/83-02

Publication date: November $30^{\text {th }} 2021$

\section{Introduction}

From the day of inception, English has been considered as an official language of Pakistan. The medium of instruction of most educational institutions, judicial and legislation is English. Despite of giving such importance, people are facing challenges while speaking it (Ahmed et al, 2020). People of Pakistan consider English as a benchmark knowing the fact that only English will help them in achieving various career opportunities. Despite of having enough knowledge in any field, it is mandatory for them to speak and write well in English language (Umrani \& Bughio, 2017). English has been the medium of communication not only in schools/intuitions but also in proceedings of courts, industrial and business areas, science and informational technologies. Hence it has its roots in every field (Haque,1982).

As per growing demand of knowing English across the globe, the fluency of English depends on four skills, in which speaking skill is one of them (Boonkit, 2010). Speaking skill has its background in legal setting, such as Roman Legal system, Asian and most continental legal system, were carried out orally (Gibbons, 2004). Professionals in Pakistan are facing lot of language issues due to which they can't perform well at their workplaces. Lawyers issue are one of them, who can't defend their cases just because of incompetency In English language. Ahmed (2006) has conducted a research in Punjab, Pakistan and claimed that lawyers do not have command over English language despite the fact their whole curriculum is in English. In the light of above description, this paper particularly focused on investigating English speaking problems of lawyers during court proceedings in Hyderabad, Sindh.

\subsection{Problem Statement}

Learning and Speaking English in Pakistan has become a problematic experience and may be one of the reasons for disturbing person's confidence level and self-esteem (Zheng, 2008). Mehlar (1961) \& Bhatia (1993) have discussed about the issues of teaching and learning legal English in foreign counties. They found that professionals have been facing serious problems during court matters, whether it be a written or spoken discourse. In Pakistan, speaking English problem of lawyers became so high that it became quite challenging to get justice. Even the Supreme court of Pakistan has given some guidelines to overcome such problems. Such as, supreme court banned three years bachelors' program of LLB and introduced five years bachelors' program of LLB from September 2019. Language problem was improved by replacing English with Urdu and by making Urdu as an official language of Pakistan (Khan, H.A, et al, 2019). Newspaper like Dawn, magazine named Herald voiced this issue by mentioning the statements of lawyers. They said that Urdu is ill-suited to be an 
official language. As both, lawyers and judges do not have training in Urdu, so, no matter what English is here to stay. Keeping this in mind, the need of improving English in the field of law, the current study intends to investigate English speaking problems of lawyers in court proceedings.

\subsection{Research Question}

The study is solely based on the research question mentioned below:

Q1. What are the problems faced by the lawyers while speaking English as a language of law?

\section{Literature Review}

Use of Speaking English in legal setting can be categorised into three types: 1) Pedagogic, which includes lectures, mock tribunals, or moots; 2) Academic, involves conferences and seminars; 3) Professional, used for the purpose of client-lawyer or judge-lawyer interaction (Bhatia, 1987). In the present study, use of English for professionals legal setting has been focused. Now Professional legal setting itself is divided into two categories: inside and outside the courtroom. In this research, client- lawyer and judge-lawyer consultation has been considered which takes place inside the courtroom. Bhatia (1987) in his research talked about client-lawyer relationship. Findings disclosed that lawyers usually use simplified language while interacting with client who is a lay man. Lawyers has always been dominant whereas client is busy understating the case. Also, there are linguistic devices developed to make the language simple by translating into commoner's language (Bhatia, 1987).

Gibbons (2004) conducted a study in which he discussed about speech errors of lawyers that holds great impact on lawyer's performance. Minor inaccuracies in vocabulary or mistakes in grammar while speaking inside the court can be the major cause of losing a case. Gibbons further added by giving suggestions that there must be a proper training for lawyers where they can practice beforehand for case proceedings (Gibbons, 2004).

Khan et al. (2019) also conducted a research in the context of Pakistan, based on the topic of reforming legal education in Pakistan, by noticing the ongoing problems that lawyers face during court proceedings and documentation. As they are incompetent in terms of knowledge as well communication so solutions at the end were found in the research. Qualitative methodology was used involving 100 participants. Participants were mostly fresh graduates and belonged to different universities across Pakistan. Their present courses were compared with the courses of Malaysia, as their courses involved practices. At the end, researchers found that Pakistan's present curriculum was lacked in practical courses which may help lawyers in practicing fields. So, at the end suggestions were found that Pakistan should adopt Malaysian learning and teaching strategies to improvise their leaning process (Khan et al, 2019).

Ahmad et al, (2019) did a research on Stylistic study of legal language in the verdicts of supreme court of Pakistan. The focus is basically on the written discourse as it covers the style of the documentation. Qualitative methodology was used to carefully analyse the articles and documentation of the legal discourse. Textual analysis was done on constitutional petition No. 56 of 2003, which based on features of language, comprehending the text, and the use of English, which is the base of stylistic aspects. The findings of the study showed that text which is mostly used in the court matter of Pakistan was basically adopted from foreign countries. People use mostly foreign laws and language which is quite challenging for people to understand. So, it was recommended that legal discourse should be written according to the context, such as Pakistani legal discourse, which may be understandable for its country's people (Ahmad et al, 2019).

Ahmad et. al, (2020) have directed a research on the use of English In the domain of legal services in Pakistan which makes the lawyers quite inaccessible to get justice. In Pakistan it has been quite challenging task for both lawyers and clients to get justice just because of language issues. As English possess an official status and Urdu as national, other languages are not given much importance. Despite having education in English, people are incompetent or couldn't perform well at their workplaces. For that purpose, study was particularly conducted in Mardan city of KPK to check upon which language people would like to prefer for case proceedings. Qualitative methodology was used to get in depth responses from participants. Findings at the end revealed that people preferred to encourage more local languages in the courts other than English and Urdu (Ahmed et al, 2020).

\section{Research Methodology}

The present study has used qualitative methodology to get a detailed response for participants. Qualitative methodology is a descriptive phenomenon which includes interaction of people, observed behaviours, opinions, beliefs, and live speeches from people regarding any issue. Qualitative data may be collected in the form of documents related to any organization, interview transcripts, tables, pictures, audio, and video records etc (Mohajan, 2018). Semi Structured interviews were conducted from lawyers of Hyderabad, Sindh who are currently practicing in their field. Semi structured interviews basically involve pre-determined open-ended questions asked by researchers to get in-depth yet focused responses (Corbin and Strauss, 2014). 


\subsection{Sampling \& Participants}

Total number of participants were $(n=5)$, who were law graduates and currently practicing in courts of Hyderabad, Sindh. The participants were selected non-randomly, according to their convenience called as convenient sampling also known as accidental sampling. In convenient sampling the target member must meet certain criteria such as easy accessibility, willingness to take part and to provide required information for the purpose of study (Taherdoost, 2016).

\subsection{Data Collection \& Analysis}

Participants were asked beforehand in which language they would like to give their interviews so they may feel ease. Participants preferred to talk in their mother tongue i.e., Sindhi and Urdu. The data was then translated from Sindhi/Urdu to English language. Thematic analysis was used to analyse the interviews. Model was adopted from Braun's and Clarke's (2006). The researcher thoroughly examined the English-speaking problems that lawyers faced. In thematic analysis the researcher first familiarised herself with the data, classified/generated initial codes, searched for possible themes, reviewed those themes to avoid repetition, named those final themes and then produced a final report (Braun and Clarke, 2006).

\section{Findings \& Discussion}

Findings of the current research revealed that lawyers were facing numerous problems in speaking English during court proceedings. These problems can be written in themes as under:

a. Difficulty in legal vocabulary

This difficulty was confessed by almost all the participants. According to the lawyers, vocabulary plays a significant role while defending their cases. Lawyers who lack in vocabulary are more likely called as incompetent in their field. One of the lawyers stated that, "we face a lot of problems in digestion of a section. Now in that contract act, there's a word, 'whilst' we moderate that word and made it 'while'. But we are totally unaware of the actual meaning of the word 'whilst." ' Legal words are usually Latin in origin and most of the lawyers don't knew these words, which makes them unable to use these words. Le, et al (2020) have talked about the importance of vocabulary and its role in effective communication.

b. Difficulty in grammar

Another issue faced by the lawyers was mistakes in grammatical structures. They said that English is not their mother tongue so they can't think in that language. When they utter sentences in English, these are full of grammatical mistakes which makes them hesitant to speak it. According to Kannan (2009), despite of English being taught as compulsory subject in Pakistan, people haven't got command over it as most of the students learn it to get good grades and just pass the examination. They just know it but can't speak it fluently. 4 out of 5 layers addressed this issue by saying that they can't figure out where to use past, present and future tenses. Statement of one of the lawyers is, "The basic thing in which we must be master at is English grammar. I feel difficulty in mostly grammar, which makes me hesitate to speak in front of court. I continuously question myself whether I'm right or wrong."

c. Difficulty at the beginning of practice

From 3 out of 5 lawyers it has been found that they faced difficulty when they were fresh graduates and just started practicing in their field. One lawyer stated, "I felt difficulty in terms of practice. Because when we present these laws and use legal vocabulary in courts, there we face actual problems. The law we study Is quite different form practical work." They felt this difficulty because of the difference in environment in universities and in courts. Lawyers are not given such platforms in universities where they can practice beforehand. They demand for similar environments that matches the practical one.

\section{Conclusion}

The current research was based on finding out the English-speaking problems of lawyers in court proceedings that caused them inaccessible to get justice. The findings of the study revealed that lawyers were facing some serious difficulties such as in legal vocabulary, grammar, and at the beginning of practice which caused them hesitant to speak English fluently. As people are already aware that English is the need of an hour so, they can't deny the importance of English or completely dimmish it. Lawyers were trying hard to speak English, no matter how many mistakes they utter. So, it can be suggested that remedial steps should be taken to improve their English. They must be given practical environment in universities where they can practice beforehand for the courts. They must be taught general plus legal English subjects in their curriculum where they can improve themselves in respective field.

\section{References}

1. Ahmad, N. (2006) Legal English - A Case for ESP, PhD Thesis, Department of English, Bahauddin Zakariya University, Pakistan. 
2. Ahmad, A., Saleem, M. M., \& Hussan, S. (2019). A Stylistic study of legal language in the verdicts of the Supreme Court of Pakistan. Pakistan Journal of Social Sciences (PJSS), 39(2).

3. Ahmad, A., Hussan, S., \& Butt, A. (2020). English in the Domain of Legal Services: Problems of Access in Pakistan. Pakistan Journal of Criminology, 12(1), 109-127.

4. Bhatia, V. K. (1987) Language of the Law. In Language Teaching: The international abstracting journal for language teachers and applied linguists, 18 (2): 228-234.

5. Bhatia, V. K. 1993. Analysing Genre: Language Use in Professional Settings. London: Longman.

6. Braun, V., \& Clarke, V. (2006). Using thematic analysis in psychology. Qualitative research in psychology, $3(2), 77-101$.

7. Boonkit, K. (2010). Enhancing the development of speaking skills for non-native speakers of English. Procedia-social and behavioral sciences, 2(2), 1305-1309.

8. Constitution of Islamic Republic of Pakistan, (1973), Islamabad: Government of Pakistan Haque, A. R. (1982) The Position and Status of English in Pakistan, World Englishes, Vol. 2, No. 1, 6-9

9. Corbin, J., \& Strauss, A. (2014). Basics of qualitative research: Techniques and procedures for developing grounded theory. Sage publications.

10. Gibbons, J. (2004) Language and the Law. In The Handbook of Applied Linguistics, A. Davies and C. Elder (Eds.). Malden, MA: Blackwell Publishing.

11. Kannan, R. (2009). Difficulties in learning English as a second language. ESP world, 8(5), 1-4

12. Khan, H. A., Dastagir, G., Hak, N. A., Hussain, F., \& Wahab, M. I. A. (2019). Reforming Legal Education In Pakistan By Introducing Clinical And Practical Aspect In The Existing Syllabus: A Key To Enhance Professionalism Within Law Graduates.

13. Le, L. P., Kettle, M., \& Pillay, H. (2020). Using corpus analysis in a needs analysis of key English vocabulary for petroleum engineers in Vietnam. Asian EFL Journal, $45-68$.

14. Mehler, I. M. (1961). Language mastery and legal training. Vill. L. Rev., 6, 201.

15. Mohajan, H. K. (2018). Qualitative research methodology in social sciences and related subjects. Journal of Economic Development, Environment and People, 7(1), 23-48

16. Retrieved from (https://www.dawn.com/news/1205686).

17. Retrieved from (https://herald.dawn.com/news/1153737)

18. Taherdoost, H. (2016). Sampling methods in research methodology; how to choose a sampling technique for research. How to Choose a Sampling Technique for Research (April 10, 2016).

19. Umrani, T., \& Bughio, F. A. (2017). Language politics and role of English in Pakistan. ARIEL-An International Research Journal of English Language and Literature, 26.

20. Zheng, Y. (2008) Anxiety and second /foreign language learning revisited. Canadian Journal for New Scholars in Education, 1(1), 1-12 